\title{
HIGH ADIPONECTIN AND TNF- $\alpha$ LEVELS IN MODERATE DRINKERS SUFFERING FROM LIVER STEATOSIS: COMPARISON WITH NON-DRINKERS SUFFERING FROM SIMILAR HEPATOPATHY
}

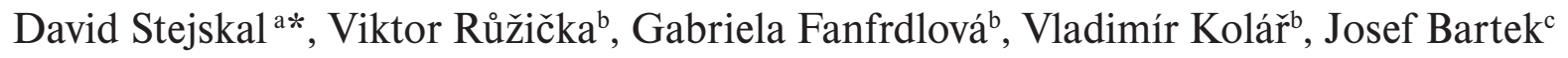 \\ a Metabolic and Diabetologic Out Patient Centre \& Department of Laboratory Medicine, Hospital Šternberk, Czech \\ Republic, \\ ${ }^{b}$ BioVendor Brno, Czech Republic \\ c Institute of Medical Chemistry and Biochemistry, Fakulty of Medicine, Palacký University Olomouc, Czech Republic \\ e-mail:david.stejskal@quick.cz
}

Received: April 7, 2005; Accepted: June 3, 2005

Key words: Adiponectin/Moderate drinking/Alcohol/Diabetes/Adipokines

Moderate alcohol consumption is associated with increased insulin sensitivity and a reduced risk for type 2 diabetes. An important endogenous mediator of insulin sensitivity is adiponectin (AN), an adipokine that displays numerous antiatherogenic, antidiabetogenic and antiinflammatory effects. Recently, acute increase in alcohol consumption has been shown to be associated with increase in plasma adiponectin and, concomitantly, insulin sensitivity. Whether chronic alcohol consumption predicts an increase in plasma AN and whether this is independent of adiposity, markers of liver dysfunction, and plasma adipokines such as tumor necrosis factor (TNF)- $\alpha$ is not known. We, therefore, investigated these relationships in 75 men who were diagnosed with liver steatosis using ultrasound/liver biopsy.

We examined 75 men, who were diagnosed for having liver steatosis (ultrasound/liver biopsy). Each filled in a questionnaire on alcohol intake. Subjects were divided into two subgroups according to alcohol history and CDT concentrations- drinkers and non-drinkers. All individuals were examined for serum concentrations of AN, glucose, triglycerides, alanine aminotransferase (ALT), aspartate aminotransferase (AST) and glutamate tranferase (GMT) activity; carbohydrate-deficient transferrin (CDT \%) a marker of chronic alcohol consumption, insulin and TNF- $\alpha$. The Quicki insulin sensitivity index was calculated.

Forty-eight individuals were found to be moderate drinkers and 27 subjects non-drinkers. Moderate drinkers had significantly higher concentrations of AN (13.8 $\pm 3,7$ versus $9.1 \pm 5.4 \mathrm{mg} / 1$, means $\pm \mathrm{SD}, \mathrm{p}=0.012)$ compared with non-drinkers, independent of adiposity. Plasma AN concentrations in the whole group were positively correlated with TNF- $\alpha$ concentrations $(r=0.6 ; p=0.0001)$, CDT $(r=0.26 ; p=0.0084)$, AST/ALT index $(r=0.3, p=0.009)$, AST $(\mathrm{r}=0.29 ; \mathrm{p}=0.011)$ and GMT $(\mathrm{r}=0.29 ; \mathrm{p}=0.011)$ and negatively with BMI $(\mathrm{r}=-0.48 ; \mathrm{p}=0.0002)$ and glycemia $(\mathrm{r}=-0.22 ; \mathrm{p}=0.049)$.

The positive associations of AN with TNF- $\alpha(0.8 ; p=0.001)$, CDT $(0.55 ; p=0.017)$, AST/ALT index $(0.55 ; p=$ $0.019)$ and the negative correlation with glycemia $(-0.35 ; \mathrm{p}=0.0158)$ were independent of BMI.

Stratified according to alcohol intake, in moderate drinkers, a positive correlation was found between AN and TNF- $\alpha$ concentrations $(r=0.6, p=0.0001$, AST/ALT index $(r=0.34, p=0.0295)$ whereas in non-drinkers no such correlations were found. The concentration of AN and BMI displayed a negative correlation in both drinker and nondrinker patients $(r=-0.42, p=0.01$ and $-0.61 ; p=0.012$, respectively).

We concluded that plasma AN is higher in moderate drinkers compared to non-drinkers, even after correction for BMI. Drinkers suffering from liver steatosis were found to have a positive correlation between AN concentrations, laboratory markers of liver disease and TNF- $\alpha$. Such correlation was absent in non-drinkers suffering from liver steatosis. This suggests that alcohol may modulate the inhibitory effect of TNF- $\alpha$ on AN production, and thus, increase its plasma concentrations.

\section{INTRODUCTION}

Adiponectin (AN) is a protein secreted by adipose tissue which displays several antiatherogenic, antidiabetogenic and antiinflammatory effects. In target tissues, it is an antagonist of TNF- $\alpha^{1-3}$. AN inhibits the production of glucose in the liver, enhances lipoprotein clearance and increases beta oxidation of fatty acids ${ }^{3-7,13}$.
Experimental and clinical studies have repeatedly confirmed that AN concentration shows a positive correlation with insulin sensitivity and a negative correlation with amount of adipose tissue. Low AN values have been associated with a high basal and reduced insulin-induced phosphorylation of tyroxin receptor for tyrosine kinase in muscle, resulting in progression of insulin resistance ${ }^{8}$. 
Low AN values typically occur in obese individuals, type 2 diabetic patients, persons with metabolic syndrome and persons with coronary artery disease (CAD). High AN values are associated with good insulin sensitivity, lower frequency of type 2 diabetes mellitus and $\mathrm{CAD}^{9-17}$.

It has been confirmed that administration of recombinant AN to mice corrected hyperglycemia (reduction of liver gluconeogenesis), decreased insulin resistance and reduced plasma atherogenicity ${ }^{3,4,9,18}$. AN also inhibits cell adhesion and neointimal formation in vessels, thus inhibiting the progression of atherosclerotic alterations ${ }^{19}$.

Moderate alcohol consumption influences many metabolic parameters positively. It is known to be associated with higher HDL concentrations, lower atherogenic risk, lower oxidative stress and higher insulin sensitivity ${ }^{20}$.

The effect of alcohol consumption on AN production and concentration in blood has not yet been investigated. At the time this paper was being prepared, two communications have been published. One was based on a mice experiment in which mice had been administered ethanol as a substantial component of caloric supply. This resulted in a significant decrease of $\mathrm{AN}$ in blood ${ }^{21}$. Another investigation made use of human volunteers who consumed alcohol for several weeks which resulted, in contrast to the mice experiment, in increased AN concentrations ${ }^{20}$.

Alcohol consumption may cause liver steatosis. Both alcohol-induced (ASH) and non-alcoholic liver steatosis (NASH) are chronic liver diseases. Their incidence is increasing and is becoming a significant cause of mortality in developed countries. ${ }^{21}$ NASH occurs mainly in indi- viduals with metabolic syndrome; almost $20 \%$ of affected individuals develop liver cirrhosis ${ }^{22,23}$.

The aim of the present study was to find relations between AN and long-term alcohol consumption with regard to TNF- $\alpha$ concentrations, insulin sensitivity and laboratory markers of liver injury in subjects with liver steatosis.

\section{METHODS}

We examined 75 men with liver steatosis diagnosed by sonography, increased laboratory markers and liver biopsy. The subjects filled in a questionnaire on frequency and quantity of alcohol intake. The study was approved by the ethical commission of the Hospital Sternberk.

The group under study was divided into two subgroups - drinkers and non-drinkers according to the following two criteria defined:

a) mean alcohol intake $>40 \mathrm{~g}$ of alcohol daily for over 4 weeks versus absolute non-drinking for the same period

b) CDT concentration (cut-off $>2.75 \%$ )

If CDT values discriminated patients into the other group than the one they specified in the questionnaire (non-drinkers with CDT $>2.75 \%$, drinkers with CDT $<2.75 \%$ ), such individuals were excluded from the study.

Blood samples was drawn under aseptic precautions from vena cubiti, samples were centrifuged $10 \mathrm{~min}$ in

Table 1. Principal statistic in whole group, subgroups of drinkers and non-drinkers.

\begin{tabular}{|l|c|c|c|c|c|c|c|c|c|c|c|}
\hline \multicolumn{9}{|c|}{$\begin{array}{c}\text { Drinkers } \\
\mathrm{n}=47\end{array}$} & \multicolumn{4}{c|}{$\begin{array}{c}\text { Non-drinkers } \\
\mathrm{n}=28\end{array}$} & \multicolumn{2}{c|}{$\begin{array}{c}\text { Statistical } \\
\text { difference }\end{array}$} \\
\hline Parameter & Unit & Mean & Median & SD & Normality & Mean & Median & SD & Normality & P & F \\
\hline AN & $\mathrm{mg} / 1$ & 13.800 & 13.600 & 5.400 & Yes & 9.100 & 9.500 & 3.700 & Yes & 0.012 & 7.300 \\
\hline AN/BMI & $\mathrm{j}$ & 0.500 & 0.460 & 0.200 & Yes & 0.260 & 0.190 & 0.120 & Yes & 0.008 & 8.200 \\
\hline AST & ukat/1 & 1.200 & 0.990 & 0.770 & Yes & 0.600 & 0.400 & 0.500 & Yes & 0.045 & 4 \\
\hline ALT & ukat/1 & 1.000 & 0.850 & 0.590 & Yes & 0.750 & 0.440 & 0.740 & Yes & NS & \\
\hline AST/ALT & $\mathrm{j}$ & 1.250 & 1.210 & 0.470 & Yes & 1.000 & 0.880 & 0.590 & Yes & NS & \\
\hline Triglycerides & $\mathrm{mmol} / 1$ & 2.400 & 1.900 & 1.500 & Yes & 1.700 & 1.400 & 0.700 & Yes & NS & \\
\hline MCV & $\mathrm{fl}$ & 93.800 & 94.000 & 6.600 & Yes & 85.800 & 86.000 & 4.900 & Yes & 0.003 & 10.300 \\
\hline BMI & $\mathrm{j}$ & 26.200 & 26.500 & 4.000 & Yes & 29.300 & 27.500 & 6.600 & Yes & NS & \\
\hline CDT & $\%$ & 3.900 & 3.300 & 1.400 & Yes & 2.000 & 2.100 & 0.340 & Yes & & \\
\hline GI & $\mathrm{mmol} / 1$ & 6.200 & 5.900 & 3.900 & Yes & 6.700 & 5.900 & 1.900 & Yes & NS & \\
\hline GMT & $\mathrm{ukat} / 1$ & 4.300 & 1.700 & 5.300 & Yes & 0.900 & 0.370 & 0.950 & Yes & 0.02 & 4.000 \\
\hline TNF- $\alpha$ & $\mathrm{pg} / \mathrm{ml}$ & 11.300 & 7.000 & 9.200 & Yes & 9.500 & 5.500 & 9.000 & Yes & NS & \\
\hline Insulin & $\mathrm{U} / \mathrm{ml}$ & 10.000 & 8.900 & 4.900 & Yes & 8.700 & 5.700 & 12.000 & Yes & NS & NS \\
\hline Quicki & $\mathrm{j}$ & 0.600 & 0.490 & 0.130 & Yes & 0.550 & 0.420 & 0.300 & Yes & NS \\
\hline Age & $\mathrm{years}$ & 53.700 & 55.000 & 10.880 & Yes & 58.500 & 58.000 & 9.700 & Yes & NS & \\
\hline
\end{tabular}

Normality assessed by Komolgorov Smirnov test 
$4{ }^{0} \mathrm{C}$ with $3000 \mathrm{~g}$ and subsequently frozen at $-80{ }^{\circ} \mathrm{C}$. All persons were examined for serum adiponectin concentration (Adiponectin, validated sandwich ELISA, Biovendor, Brno, The Czech Republic) with satisfying analytical characteristics (intrassay coefficient of variation $(\mathrm{CV})=5.4 \%$, interassay $\mathrm{CV}=6.8 \%)$, glucose $($ Glucose GOD-POD, Biovendor), triglycerides (Triglycerides, Biovendor), activity of ALT (ALT, Biovendor), AST (AST, Biovendor) and CDT \% (Axis-Shield, Oslo, Norway), insulin (Insulin, DPC, USA, California, Los Angeles) and TNF- $\alpha$ (TNF- $\alpha$, DPC, California, Los Angeles). Insulin and glycemia were taken for calculating the insulin sensitivity index (Quicki).

Body weight of patients was measured in their underwear, without any belongings (keys, shoes etc.).

Statistical data were processed by the Medcalc software (Medcalc, Mariakerke, Belgium).

\section{RESULTS}

Forty eight probands were classified as moderate drinkers, twenty seven as non-drinkers. Four subjects were excluded due to differences between anamnestic information on alcohol consumption and corresponding CDT \% values (see Methods).

Normal distribution of all parameters was found in both subgroups (drinkers and non-drinkers).

Moderate drinkers had significantly higher serum adiponectin concentrations (mean $13.8 \mathrm{vs} 9.1 \mathrm{mg} / 1$ ) and adiponectin after correction to BMI compared to nondrinkers ( 0.5 vs 0.26$)$. They also showed higher activities of AST, GMT as well as higher medium erythrocyte volume (MCV) compared to non-drinkers.

Other parameters did not differ significantly (Table 1, Fig. 1, Fig. 2).

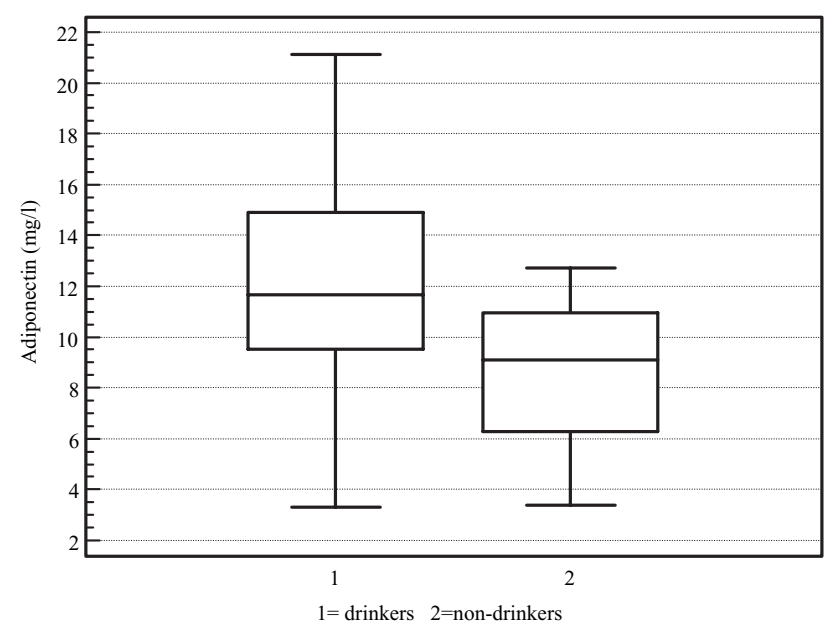

Fig. 1. Serum adiponectin levels in drinkers and non-drinker pacients with liver steatosis.

The results are represented by a whisker box plot where the upper and the lower boundary of the box and the line within the box indicate the $75^{\text {th }}$ and $25^{\text {th }}$ percentiles and the median, respectively. The error bars above and below the box indicate the $90^{\text {th }}$ and $10^{\text {th }}$ percentiles.

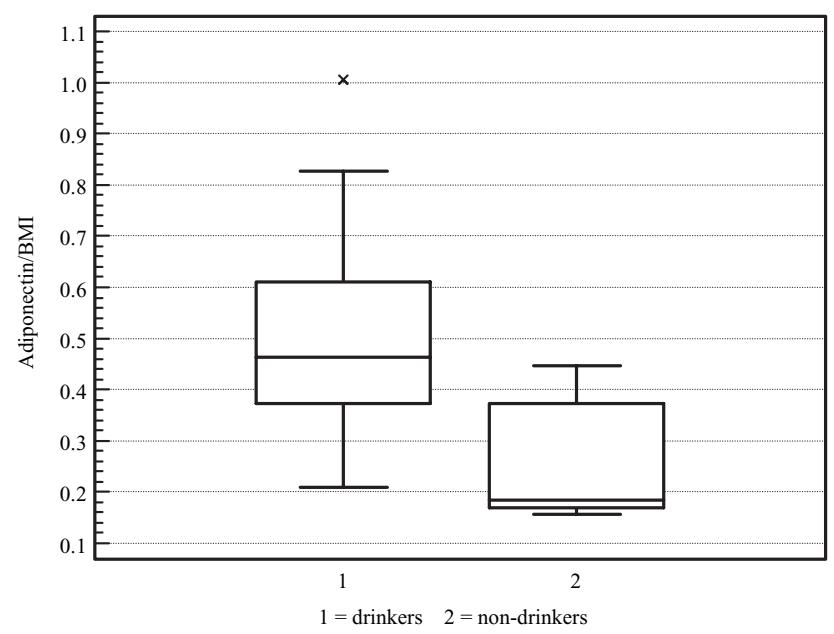

Fig. 2. Body mass index (BMI) - normalized serum adiponectin levels in drinkers and non-drinker patients with liver steatosis.

The results are represented by a whisker box plot where the upper and the lower boundary of the box and the line within the box indicate the $75^{\text {th }}$ and $25^{\text {th }}$ percentiles and the median, respectively. The error bars above and below the box indicate the $90^{\text {th }}$ and $10^{\text {th }}$ percentiles.

All probands showed a significant positive correlation between adiponectin and TNF- $\alpha(\mathrm{r}=0.6, \mathrm{p}=0.0001$, Spearman $)$ CDT \% $(r=0.26, p=0.0084$, Spearman $)$, AST/ALT index $(r=0.3 ; p=0.009$, Spearman $)$, and AST $(r=0.29 ; p=0.011$, Spearman $)$ as well as GMT $(r=0.29$; $\mathrm{p}=0.011$, Spearman) and a negative correlation with BMI $(r=-0.48 ; p=0.0002$, Spearman $)$ and glycemia ( $\mathrm{r}=-0.22, \mathrm{p}=0.049$, Spearman $)$.

Normalisation of adiponectin values to BMI further strengthened the correlations: TNF- $\alpha(r=0.8 ; p=0.001$, Spearman), CDT ( $r=0.55 ; \mathrm{p}=0.017$, Spearman), AST/ ALT index $(r=0.55 ; p=0.019$, Spearman $)$, glycemia $(r=-0.35 ; p=0.0158$, Spearman) (Table 2, Fig. 3-4).

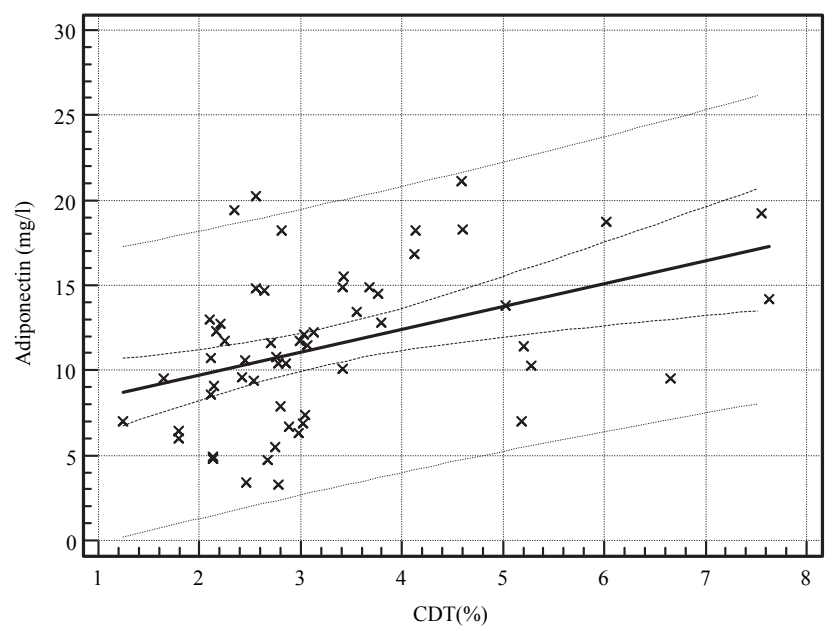

Fig. 3. Scatter, adiponectin and CDT \%. 


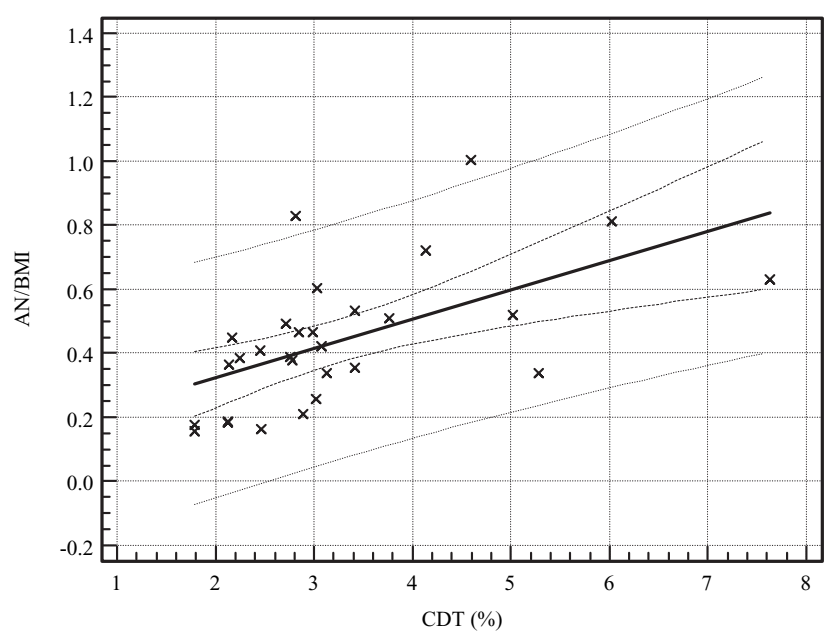

Fig. 4. Scatter, adiponectin/BMI and CDT\%.

Dividing the cohort according to alcohol intake showed that a positive correlation between serum adiponectin with TNF- $\alpha(\mathrm{r}=0.6 ; \mathrm{p}=0.0001)$ and between serum AN and AST/ALT index $(r=0.34 ; p=0.0295)$ was found in drinkers only. A negative correlation of AN with BMI was found in both drinkers $(\mathrm{r}=-0.42 ; \mathrm{p}=0.01)$ and non-drinkers $(\mathrm{r}=-0.61 ; \mathrm{p}=0.012)$ (Table 3$)$.

In drinkers, AN/BMI index correlated positively with TNF- $\alpha$ concentration $(r=0.64 ; p=0.041$, Spearman $)$, AST/ALT index $(r=0.72 ; p=0.0005$, Spearman $)$ and negatively with triglycerides concentration $(\mathrm{r}=-0.55$; $\mathrm{p}=0.045$, Spearman). Non-drinkers showed only a distinct negative correlation between glycemia and adiponectin $(r=-0.72 ; p=0.045$, Spearman) (Table 4).

Drinkers revealed a positive correlation between CDT and TNF- $\alpha(r=0,5 ; p=0,041)$ and between CDT and
AST $(r=0,43 ; p=0,02)$. In non-drinkers, a significant negative correlation was found between TNF- $\alpha$ and the Quicki index of insulin sensitivity $(r=-0.42 ; p=0,032)$ (Table 5).

The stepwise variable regression showed that out of all measured parameters only the adiponectin value could be used to calculate the regression formula to assess drinkers (F 8.44; $p=0.0103, R^{2} 0.35$ ) (of course, except for CDT \% which was used for defining this subgroup).

The values of AN/BMI index $>0.19$ had $100 \%$ sensitivity and $63 \%$ specificity for identifying drinkers (Fig. 6).

To illustrate the diagnostic validity of AN/BMI for identifying drinkers, the ROC curves for adiponectin/ BMI were compared with GMT and Mean Erythrocyte (Corpuscular) Volume (MCV). The resulting Areas Under Curve (AUC) did not differ significantly and all three were of diagnostic value (AUC for adiponectin/BMI was 0.89 (95\% CI 0.67-0.96), AUC for GMT was 0.81 (95\% CI 0.61-0.93) and AUC for MCV was 0.84 (95\% CI 0.64-0.93) (Fig. 7).

\section{DISCUSSION}

Liver steatosis is characterized by overproduction of inflammatory cytokines (TNF- $\alpha$, Interleukin- $1 \beta$ a Interleukin-6) by activated Kupffer cells and by imbalance of the production of inflammatory and anti-inflammatory cytokines in the liver $^{24-27}$ reducing adiponectin expression in adipose tissue ${ }^{28,29}$.

Anti-inflammatory cytokines have hepatoprotective effect ${ }^{27}$. Decreased concentration of Interleukin-10 in mice model after alcohol intake or its absence in Interleukin-10 knockout mice leads to a markedly enhanced incidence of hepatic necrosis ${ }^{30}$.

Table 3. Correlation, adiponectin and others.

\begin{tabular}{|cccc|cccc|}
\hline Drinkers & Parameter & Corr coef & $\mathrm{p}$ & Non-drinkers & Parameter & Corr coef & $\mathrm{p}$ \\
\hline AN & BMI & $(-) 0.420$ & 0.01 & AN & BMI & $(-) 0.61$ & 0.0120 \\
& AST/ALT & 0.340 & 0.0295 & & & & \\
& TNF- $\alpha$ & 0.600 & 0.0001 & & & & \\
\hline
\end{tabular}

Table 4. Correlation, adiponectin BMI and others.

\begin{tabular}{|cccc|cccc|}
\hline Drinkers & Parameter & Corr coef & $\mathrm{p}$ & Non-drinkers & Parameter & Corr coef & P \\
\hline AN/BMI & AST/ALT & 0.38 & 0.0381 & AN/BMI & Gl & $(-) 0.43$ & 0.048 \\
\hline
\end{tabular}

Table 5. Correlation, others.

\begin{tabular}{|cccc|cccc|}
\hline Drinkers & Parameter & Corr coef & $\mathrm{p}$ & Non-drinkers & Parameter & Corr coef & $\mathrm{p}$ \\
\hline CDT & AST & 0.43 & 0.02 & & & & \\
CDT & TNF- $\alpha$ & 0.5 & 0.041 & TNF- $\alpha$ & Quicki & $(-) 0.42$ & 0.032 \\
\hline
\end{tabular}




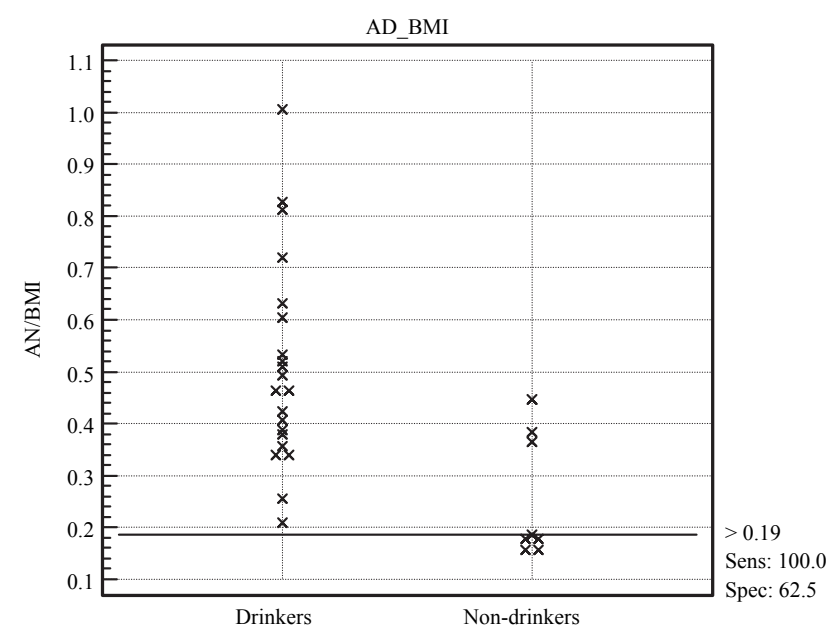

Fig. 6. ROC Adiponectin/BMI.

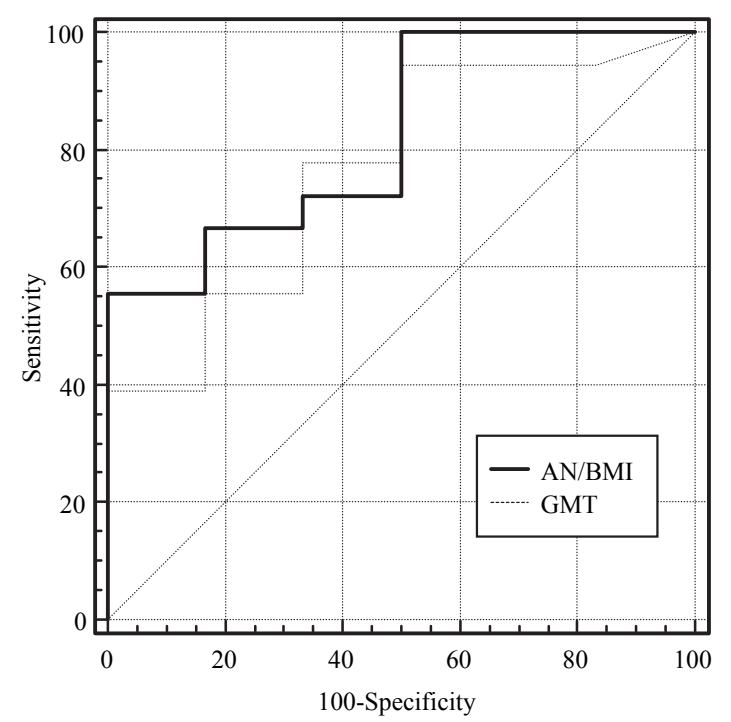

Fig. 7. Comparison of ROC curves for AN/BMI and GMT.

The alcohol-induced hepatic involvement is also markedly reduced by administration of antibodies against TNF- $\alpha^{31}$ and completely eliminated in TNF- $\alpha$ receptor 1 knock-out mice model ${ }^{32}$. In addition, therapy with thalidomid (inhibitor of TNF- $\alpha$ production in Kupffer cells) inhibits alcohol-induced liver injury ${ }^{11}$.

High concentrations of TNF- $\alpha$ lead to high basal phosphorylation of muscle insulin receptor and is manifested as insulin resistance ${ }^{34,35}$.

In general, $\mathrm{AN}$ and $\mathrm{TNF}-\alpha$ are antagonist proteins. TNF- $\alpha$ is considered a causal factor of insulin resistance. By contrast, AN enhances insulin sensitivity ${ }^{2,3}$. AN displays antiatherogenic effects ${ }^{36,37}$, TNF- $\alpha$ leads to progression of atherosclerosis ${ }^{33,38}$.

One experimental study showed that administration of AN resulted in decreased production of TNF- $\alpha$ by the liver and reduced concentration of TNF- $\alpha$ in circulation ${ }^{39}$. These findings were also confirmed in adiponectin-knockout mice models, where high expression and production of TNF- $\alpha$ were demonstrated ${ }^{4}$.
Enhanced expression of cytokines and chemokines, such as TNF- $\alpha$, Interleukin-6, Interleukin-18, MCP-1 and resistin is also typical of obese individuals. Obese adipose tissue is infiltrated by cells of monocyte origin producing such peptides ${ }^{20}$.

This suggests that the conditions leading to enhanced production and activity of cytokines and chemokines (e.g. liver steatosis or obesity) are associated with low levels of adiponectin. However, the very opposite was recorded in our group of alcohol drinkers.

These findings lead us to the hypothesis that alcohol blocks the inhibitory effect of one or more anti-inflammatory factors (e.g.TNF- $\alpha$ ) on adiponectin expression and secretion.

Extensive literature documents that chronic alcohol consumption in humans is related to enhanced insulin sensitivity. Many prospective studies proved have shown regular alcohol intake (so-called moderate drinking) is associated with augmented type 2 diabetes and cardiovascular mortality ${ }^{40-44}$. We found three experimental studies dealing with a direct impact of chronic alcohol abuse on insulin sensitivity. One of them reported a significant increase in insulin sensitivity after moderate alcohol intake in 51 postmenopausal women ${ }^{44}$, two other studies proved that alcohol had no significant effect on the parameters of insulin sensitivity ${ }^{12,42-43}$.

The absence of an effect of chronic alcohol intake on insulin sensitivity in these studies might be due to an insufficient daily alcohol dose, short follow-up and many other factors.

A recent study employing healthy volunteers ${ }^{20}$ revealed that regular alcohol intake did not only lead to a decrease but to an increase of AN concentrations and enhanced insulin sensitivity (by $11 \%$ after a 4 -week consumption of $40 \mathrm{~g}$ alcohol/day). TNF- $\alpha$ levels did not change significantly due to drinking. This makes us conclude that similar TNF- $\alpha$ levels in both drinkers and non-drinkers lead to attenuated inhibition of adiponectin expression and/or secretion in drinkers and, subsequently, to higher adiponectin levels measured in circulation.

If alcohol intake results in reduction of the inhibitory effect of TNF- $\alpha$ on adiponectin expression and/or secretion, it may be speculated that alcohol also eliminates or blocks other effects of TNF- $\alpha$ which are causal or supportive on the emergence and propagation of metabolic syndrome and atherosclerosis.

To clarify all these relations, extensive experiments should be carried out, particularly at the molecular level.

\section{AKNOWLEDGEMENT}

This study was supported by grantes VVZ MSM 6198959216 from the Ministry of Education, Youth and Sports of the Czech Republic, IGA IA/8250-2/2004 and 1A/8250-2/2004 from the Ministry of Health of the Czech Republic and IGA. 


\section{REFERENCES}

1. Brunt EM. (2001) Nonalcoholic steatohepatitis: definition and pathology. Semin Liver Dis 21, 3-16.

2. Li Z (2003) Probiotics and antibodies to TNF- $\alpha$ inhibit inflammatory activity and improve nonalcoholic fatty liver disease. Hepatology 37, 343-350.

3. Fruebis J. (2001) Proteolytic cleavage product of 30-kDa adipocyte complement-related protein increases fatty acid oxidation in muscle and causes weight loss in mice. Proc. Nat. Acad. Sci. USA 98 2005-2010.

4. Berg AH, Combs TP, Scherer PE. (2002) ACRP30/adiponectin: an adipokine regulating glucose and lipid metabolism. Trends Endocrinol Metab 13, 84-89.

5. Shapiro L, Scherer PE. (1998) The crystal structure of a complement-1q family protein suggests an evolutionary link to tumor necrosis factor. Curr. Biol 8, 335-338.

6. Maeda N (2002) Diet-induced insulin resistance in mice lacking adiponectin/ACRP30. Nat. Med. 8, 731-737.

7. Havel PJ. (2002) Control of energy homeostasis and insulin action by adipocyty hormones: leptin, acylation stimulating protein, and adiponectin. Curr Opin Lipidol 13, 51-59.

8. Stefan N, Vozarova B, Funahashi T, Matsuzawa Y, Weyer C, Lindsay RS, Youngren JF, Havel PJ, Pratley RE, Bogardus C, Tatarann PA. (2002) Plasma adiponectin concentration is associated with skeletal muscle insulin receptor tyrosin phosphorylation, and low plasma concentration precedes a decrease in whole-body insulin sensitivity in humans. Diabetes 50, 1884-1888.

9. Fruebis J. (2001) Proteolytic cleavage product of 30-kDa adipocyte complement-related protein increases fatty acid oxidation in muscle and causes weight loss in mice. Proc. Nat. Acad. Sci. USA 98, 2005-2010.

10. Hotta K. (2001) Circulating concentrations of the adipocyte protein adiponectin are decreased in parallel with reduced insulin sensitivity during the progression to type 2 diabetes in rhesus monkeys. Diabetes 50, 1126-1133

11. Lin HZ, Yang SQ, Zeldin G, Diehl AM. (1998) Chronic ethanol consumption induces the production of tumor necrosis factor-alpha and related cytokines in liver and adipose tissue. Alcohol. Clin. Exp. Res 22, 231-237.

12. Weyer C, Funahashi T, Tanaka S, Hotta K, Matsuzawa Y, Pratley RE, Tataranni A. (2001) Hypoadiponectinemia in obesity and type 2 diabetes: close association with insulin resistance and hyperinsulinemia. J Clin Endocrinol Metab 86, 1930-1935.

13. Hotta K, Funahashi T, Bodkin NL, Ortmeyer HK, Arita Y, Hansen BC, Matsuzawa Y. (2001) Circulating concentrations of the adipocyte protein adiponectin are decreased in parallel with reduced insulin sensitivity during the progression to type 2 diabetes in rhesus monkeys. Diabetes 50, 1126-1133.

14. Hotta K, Funahashi T, Arita Y, Takahsashi Y, Matsuda M, Okamoto Y, Iwahashi H, Kuriyama H, Ouchi N, Maeda K, Nishida M, Kihara S, Sakayi N, Nakajima T, Hasegawa K, Muraguchi M, Ohmoto Y, Nakamura T, Yamashita S, Hanafusa T, Matsuzawa Y (2000) Plasma concentrations of a novel adipose-specific protein, adiponectin, in type 2 diabetic patients. Arterioscler Thromb Vasc Biol 20, 1595-1599.

15. Ouchi N, Kihara S, Arita Y, Maeda K, Kuriyama H, Okamoto Y, Hotta K, Nishida M, Takahashi M, Nakamura T, Yamashita S, Funahashi F, Matsuzawa Y. (1999) Novel modulator for endothelial adhesion molecules: adipocyte-derived plasma protein adiponectin. Circulation 100, 2473-2476.

16. Arita Y, Kihara S, Ouchi N, Takahashi M, Maeda K, Miyagawa J, Hotta K, Himomura I, Nakamura T, Miyaoka K, Kuriyama H, Nishida M, Yamashita S, Okubo K, Matsubara K, Muraguch M, Ohmoto Y, Funahashi T, Matsuzawa Y. (1999) Paradoxica decrease of an adipose-specific protein, adiponectin, in obesity. Biochem Biophys Res Commun 257, 79-83.

17. Berg AH. (2001) The adipocyte-secreted protein Acrp30 enhances hepatic insulin action. Nat Med 7, 947-953
18. Yokota T. (2000) Adiponectin, a new member of the family of soluble defense collagens, negatively regulates the growth of myelomonocytic progenitors and the functions of macrophages. Blood 96, 1723-1732.

19. Sierksma A, Patel H, Ouchi N, Kihara S, Funahashi T, Heine RJ, Grobbee DE, Kluft C, Hendriks HF. (2004) Effect of moderate alcohol consumption on adiponectin, tumor necrosis factor-alpha, and insulin sensitivity. Diabetes Care 27, 184-189.

20. Xu A Wang Y, Keshaw H. (2003) The fat-derived hormone adiponectin alleviates alcoholic and nonalcoholic fatty liver disease in mice. J Clin Invest 112, 91-100.

21. Yin M. (1999) Essential role of tumor necrosis factor alpha in alcohol-induced liver injury in mice. Gastroenterology 117, 942-952.

22. Enomoto N. (2002) Thalidomide prevents alcoholic liver injury in rats through suppression of Kupffer cell sensitization and TNFalpha production. Gastroenterology 123, 291-300.

23. Diehl AM. (2002) Nonalcoholic steatosis and steatohepatitis IV. Nonalcoholic fatty liver disease abnormalities in macrophage function and cytokines. Am J Physiol 282, 1-5.

24. Molina PE. (2002) Molecular pathology and clinical aspects of alcohol-induced tissue injury. Alcohol Clin Exp Res 26, 120-128.

25. Stewart S, Jones D, Day CP. (2001) Alcoholic liver disease: new insights into mechanisms and preventative strategies. Trends Mol Med 7, 408-413.

26. Diehl AM. (2000) Cytokine regulation of liver injury and repair. Immunol Rev 174, 160-171.

27. Hasshauer M. (2002) Hormonal regulation of adiponectin gene expression in 3T3-L1 adipocytes. Biochem. Biophys Res Commun 290, 1084-1089.

28. Wilkes JJ, DeForrest LL, Nagy LE. (1996) Chronic ethanol feeding in a high-fat diet decreases insulin-stimulated glucose transport in rat adipocytes. Am J Physiol 271, 477-484.

29. Limuro Y. (1997) Antibodies to tumor necrosis factor alpha attenuate hepatic necrosis and inflammation caused by chronic exposure to ethanol in the rat. Hepatology 26, 1530-1537.

30. McClain CJ. (1999) Cytokines in alcoholic liver disease. Semin. Liver Dis 19, 205-219.

31. Adachi Y. (1994) Inactivation of Kupffer cells prevents early alcohol-induced liver injury. Hepatology 20, 453-460.

32. Jarvelainen HA. (2000) Kupffer cell inactivation alleviates ethanolinduced steatosis and CYP2E1 induction but not inflammatory responses in rat liver. J. Hepatol 32, 900-910.

33. Burant CF. (1997) Troglitazone action is independent of adipose tissue. J. Clin Invest 100, 2900-2908.

34. Hotamisligil GS, Shargill NS, Spiegelman BM. (1993) Adipose expression of tumor necrosis factor-[alpha]: direct role in obesitylinked insulin resistance. Science 259, 87-91.

35. Ouchi N. (1999) Novel modulator for endothelial adhesion molecules: adipocyte-derived plasma protein adiponectin. Circulation 100, 2473-2476.

36. Ross R. (1999) Atherosclerosis: an inflammatory disease. New Engl J Med 340, 115-126.

37. Combs TP. (2001) Endogenous glucose production is inhibited by the adipose-derived protein Acrp30. J Clin Invest 108, 18751881.

38. Yamauchi T (2002) Adiponectin stimulates glucose utilization and fatty-acid oxidation by activating AMP-activated protein kinase. Nat Med 8, 1288-1295.

39. Yoda M. (2001) Change in expression of GBP28/adiponectin in carbon tetrachloride-administrated mouse liver. Biochem Biophys Res Commun 285, 372-377.

40. Razay G, Heaton KW. (1992) Alcohol consumption and its relation to cardiovascular risk factors in British women. BMJ 304, 80-83.

41. Mayer EJ, Newman B, Quesenberry CP, Friedman GD, Selby JV. (1993) Alcohol consumption and insulin concentrations: role of insulin in associations of alcohol intake with high-density lipoprotein cholesterol and triglycerides. Circulation 88, 2190-2197.

42. Facchini F, Chen YD, Reaven GM. (1994) Light-to-moderate alcohol intake is associated with enhanced insulin sensitivity. Diabetes Care 17, 115-119. 
High adiponectin and TNF-a levels in moderate drinkers suffering from liver steatosis: comparison with non-drinkers suffering from similar hepatopathy

43. Kiechl S, Willeit J, Poewe W, Egger G, Oberhollenzer F, Muggeo M, Bonora E. (1996) Insulin sensitivity and regular alcohol consumption: large, prospective, Gross sectional population study (Bruneck Study). BMJ 313, 1040-1044.
44. Davies MJ, Baer DJ, Judd JT, Brown ED, Campbell WS, Taylor PR. (2002) Effects of moderate alcohol intake on fasting insulin and glucose concentrations and insulin sensitivity in postmenopausal women: a randomized controlled trial. JAMA 287, 2559-2562. 